\title{
Em tempos de ensino remoto: praticando Matemática no Google Forms a partir de um boletim epidemiológico sobre o Coronavírus-Covid-19
}

\author{
In times of remote teaching: practicing Mathematics on Google Forms from an \\ epidemiological bulletin on Coronavirus-Covid-19
}

\author{
Marcos Antônio Guedes Caetano ${ }^{1}$ \\ Secretaria da Educação do Estado da Bahia (SEC/BA) \\ Secretaria Municipal de Educação de Caravelas (SEMED), Caravelas, BA, Brasil \\ https://orcid.org/0000-0002-2118-406X, 9 http://lattes.cnpq.br/6328853400116537
}

\begin{abstract}
Resumo: Este trabalho visa tecer considerações sobre o desenvolvimento de uma atividade matemática remota junto aos alunos do $6^{\circ}$ ano da Escola Municipal Claudionora Nobre de Melo, situada no município de Caravelas. A condução dessa prática pedagógica teve como ponto de partida um boletim epidemiológico sobre o Coronavírus-Covid-19 referente a esta localidade do Extremo Sul da Bahia. Tal estudo se justifica pelo fato de ser uma estratégia que possibilita o diálogo entre duas vertentes: o momento pandêmico atual e o conhecimento matemático, favorecendo assim o aprendizado dos conteúdos matemáticos. Nessa perspectiva, lança mão da metodologia de resolução de problemas a partir de situações matematizadas e com base nas reflexões freireanas, que propõe viabilizar a convivência com a Matemática, criando condições para que esse conhecimento seja construído. Com este direcionamento, apoia-se também na BNCC que retrata esse aspecto metodológico como um instrumento privilegiado no processo de ensino e aprendizagem do ensino fundamental. Para tanto, recorre ao Google Forms como recurso pedagógico e tecnológico, subsidiando o presente estudo e como forma de despertar o interesse do aluno. Tudo indica que fomentar ações de natureza interdisciplinar diversifica, dinamiza e enriquece o binômio ensinar e aprender de Matemática, o que de certo modo também estabelece relações entre o objeto matemático e acontecimentos reais vinculados às vivências dos alunos, como as questões de âmbito social, voltadas à área de saúde. São contextos viáveis e significativos de construção do exercício matemático.
\end{abstract}

Palavras-chave: Matemática; Resolução de Problemas; Covid-19; Google Forms.

Abstract: This work aims to make considerations about the development of a remote mathematics activity with the students of the 6th year of the School Claudionora Nobre de Melo, located in the city Caravelas. The conduction of this pedagogical practice started with an epidemiological bulletin on the Coronavirus-Covid-19 found in this location, in the extreme south of Bahia. Such a study is justified by the fact that it is a strategy that enables dialogue between two aspects: the current pandemic moment and mathematical knowledge, thus favoring the learning of mathematical contents. In this perspective, it makes use of the problem-solving methodology based on mathematical situations and based on Paulo Freire's reflections, which proposes the improvement of the contact with Mathematics, creating conditions for this knowledge to be built. With this direction, it also relies on the BNCC, which portrays this methodological aspect as a privileged instrument in the teaching and learning process of elementary education. To do so, it uses the Google Forms as a pedagogical and technological resource, subsidizing the present study and as a way of arousing the student's interest. Everything indicates that promoting actions of an interdisciplinary nature diversifies, dynamizes, and enriches the binomial teaching and learning of Mathematics, which in a way also establishes relationships between the mathematical object and real events linked to the students' experiences, such as social issues, focused on the health area. These are viable and significant contexts for the construction of mathematical exercises.

Keywords: Mathematics; Problem Solving; Covid-19; Google Forms.

Data de submissão: 23 de janeiro de 2021.

Data de aprovação: 10 de abril de 2021.

\footnotetext{
${ }^{1}$ Currículo sucinto: Licenciado em Pedagogia pela Universidade do Estado da Bahia (UNEB) e em Matemática pela Universidade Salvador (UNIFACS), mestre em Educação Matemática pela Universidade de Vassouras. Contribuição de autoria: Administração do projeto, análise formal, escrita - primeira redação. Contato: marcosantonioguedescaetano1@gmail.com.
} 


\section{Introdução}

Muitos são os caminhos para a abordagem de ideias, reflexões, conceitos e procedimentos matemáticos. Conhecer essas trilhas, segundo Onuchic (2012), é um dos pontos que se insere como algo positivo para a melhoria da educação matemática. Por quê? No entendimento dessa autora, o conceito de professores excelentes perpassa pela importância de conhecermos sobre esses caminhos diversos, o que para ela traz benefícios, ajudando o aluno em torno da aprendizagem matemática. Nessa linha de raciocínio, (SKOVSMOSE, 2000 apud SERRAZINA; RIBEIRO, 2012), cita que a diversidade de tarefas propostas aos alunos, estimula uma educação matemática que facilita o desenvolvimento do pensar matematicamente. Acredita-se, assim como Freire (1996b) que é preciso criar condições para que o conhecimento seja construído. E nessa criação, a simplicidade e a naturalidade do exercício matemático são fundamentais.

Para tanto, o desenvolvimento das atividades tanto fora quanto dentro da sala de aula, segundo Groenwald, Silva e Mora (2004), tendo em vista o pensamento filosófico fundamentado na educação matemática crítica, não pode prescindir de estratégias metodológicas de aprendizagem ativas e problematizadas, tais como a resolução de problemas, a modelagem matemática, o uso crítico da tecnologia, dentre outras. Acredita-se, assim, que a variedade de situações didático-pedagógicas propostas nas questões de ensino e aprendizagem tende-se a tornar os processos matemáticos mais enriquecidos, dinâmicos, interativos e significativos. Porém, não se pode cometer esse equívoco: esquecer a realidade humana, sua situação presente e existente, conforme enfatiza Freire (1987).

Acrescenta-se a essas considerações, a necessidade que essa área articulada com seus diferentes campos, precisa garantir ao público do ensino fundamental de acordo com a Base Nacional Comum Curricular (BNCC) que: "relacionem observações empíricas do mundo real a representações (tabelas, figuras e esquemas) e associem essas representações a uma atividade matemática (conceitos e propriedades), fazendo induções e conjecturas" (BRASIL, 2018, p. 265). Nessa perspectiva, conforme explicita esse documento, é esperado o desenvolvimento de habilidades por parte dos alunos que gere a identificação de oportunidades, levando-os a utilizar o conhecimento matemático, tendo em vista à resolução de problemas. Isso será feito por meio da aplicação de "conceitos, procedimentos e resultados para obter soluções e interpretá-las segundo os contextos das situações" (BRASIL, 2018, p. 265).

A partir desse enfoque, considerando ainda o ensino remoto adotado por muitas escolas na atualidade, devido ao momento pandêmico da Covid-19 que, infelizmente, o mundo está vivenciando, buscou-se nessa atividade aplicada junto aos alunos do $6^{\circ}$ ano da Escola Municipal Claudionora Nobre de Melo um diálogo entre a Matemática e as informações alusivas a esta pandemia. "Porque não estabelecer uma necessária 'intimidade' entre os saberes curriculares 
fundamentais aos alunos e a experiência social que eles têm como indivíduos?" (FREIRE, 1996a, p. 17).

Esta unidade de ensino está localizada na sede do município de Caravelas-BA, ofertando o ensino fundamental II, bem como a EJA no turno noturno. Os participantes da pesquisa estão distribuídos em duas turmas de $6^{\circ}$ ano $(A$ e $B$ ), turno matutino, totalizando 55 alunos, e tem como regente, o professor-pesquisador. Boa parte desses alunos tem acesso à internet, embora esse acesso muitas vezes acontece de forma limitada. Diante desse contexto, o intuito deste trabalho em linhas gerais é que estes alunos, com faixa etária que variam entre 10 e 14 anos, pudessem estabelecer uma relação entre essas duas vertentes, quer dizer, praticar Matemática e ficar ao mesmo tempo a par das informações que refletem os dados numéricos do contexto pandêmico local.

É consenso entre diferentes autores, uma educação matemática partir de contextos reais, preferencialmente, ligados à realidade do aluno. É também "fundamental na preparação para a cidadania o domínio de um conteúdo relacionado com o mundo atual" (D’AMBRÓSIO, 1996, p. 86). Segundo a BNCC a aprendizagem em Matemática voltada ao público escolar - anos finais do ensino fundamental, assim também como está previsto na fase anterior - anos iniciais, está ligada à apreensão dos significados dos objetos matemáticos. Significados esses que "resultam das conexões que os alunos estabelecem entre os objetos e seu cotidiano, entre eles e os diferentes temas matemáticos e, por fim, entre eles e os demais componentes curriculares" (BRASIL, 2018, p. 298).

Com este direcionamento, utilizou-se um boletim epidemiológico sobre o CoronavírusCovid-19 que retrata dados sobre o município de Caravelas, Extremo Sul da Bahia. São informações que representam o panorama da conjuntura virótica local: número de casos confirmados, recuperados, em isolamento, em monitoramento, descartados, notificados, etc. A ideia era que o aluno pudesse desenvolver o raciocínio matemático através de situaçõesproblema propostas a partir da leitura, análise e interpretação dessas informações contidas nesse boletim. Para tanto, lançou mão do Formulário Google, onde as questões foram disponibilizadas, acessadas e respondidas pelos alunos. Despertar o interesse nas atividades remotas, que também representa um objetivo específico deste trabalho, foi um dos motivos para a escolha dessa ferramenta pedagógica e tecnológica.

Constatou-se através da análise dos dados obtidos, a partir das respostas registradas nos formulários, um aproveitamento satisfatório por parte dos alunos. Como a ideia era retomar a aprendizagem de conteúdos estudados por eles em anos anteriores, percebeu-se um desempenho melhor nas questões relacionadas às operações básicas, objeto de conhecimento matemático trabalhado ao longo dos primeiros anos escolares. Já na questão envolvendo cálculos percentuais, observou-se um menor aproveitamento. Diante de tal resultado, é necessário uma 
abordagem posterior tendo em vista este conceito. Em suma, a atividade como um todo teve uma boa aceitação dos alunos. A prova disso é que de acordo com a equipe gestora da escola, esse tipo de atividade registrou uma maior participação dos discentes.

Esta experiência comprova que promover uma relação dialógica e interdisciplinar no processo educacional, nesse estudo em particular, entre o conhecimento matemático e a pandemia atrelada ao novo coronavírus, é uma maneira de tornar significativas as questões de ensino e aprendizagem. Tem-se em mente que aproximar a Matemática e as situações que os alunos vivenciaram e/ou estão vivenciando, que de algum modo estão incorporadas e ligadas ao seu cotidiano, à sua realidade social são formas viáveis de conduzir e desenvolver a atividade matemática. Essa discussão em torno da importância de se estabelecer uma relação entre Matemática e realidade também é percebida em Caetano (2020a). Portanto, devido à relevância dessa proximidade, isso se faz necessário tanto no ensino oferecido remotamente, quanto presencialmente.

\section{Tecendo considerações sobre a atividade matemática disponibilizada no Google Forms a partir de um boletim epidemiológico - Coronavírus-Covid-19}

Como mencionado anteriormente, a atividade matemática proposta no Google Forms teve como referência um boletim epidemiológico que expressa os dados numéricos sobre a pandemia local. Presume-se que instrumentos didáticos como esse boletim, associado ao uso de recursos tecnológicos como essa ferramenta do Google, além de diversificar a abordagem matemática, tende a tornar esse processo de construção mais atrativo e significativo. Onuchic (2012), que traz considerações significativas sobre a resolução de problemas na educação matemática, defende o uso da nova tecnologia como uma coisa necessária para a sua melhoria. Santos (2020), na Revista Nova Escola, sinaliza que o Google Forms, assim denominado popularmente, configurouse como um dos instrumentos pedagógicos que se mostrou mais eficiente dentro do ensino remoto e relacionado a esse momento pandêmico. Por que então, não possibilitar essa ferramenta tecnológica?

$\mathrm{Na}$ visão de alguns educadores entrevistados por essa revista (2020) e que estão utilizando formulários no desenvolvimento de suas aulas, criando e compartilhando com seus alunos esses recursos, são muitas as vantagens dessa ferramenta: propicia a formulação de perguntas com respostas discursivas ou objetivas; o aparelho não fica sobrecarregado, pois o seu espaço de armazenamento interno não é afetado; se ajusta à tela conforme o dispositivo utilizado; facilita e agiliza a entrega das atividades; gera gráfico e planilha, potencializando a correção das atividades; permite incluir fotos, vídeos, dentre outros, ficando interativo e chamativo. Esse visual pode ser percebido na Figura 1, conforme imagem do boletim que foi anexado ao formulário criado para esta atividade matemática entrelaçada as informações da Covid-19. 


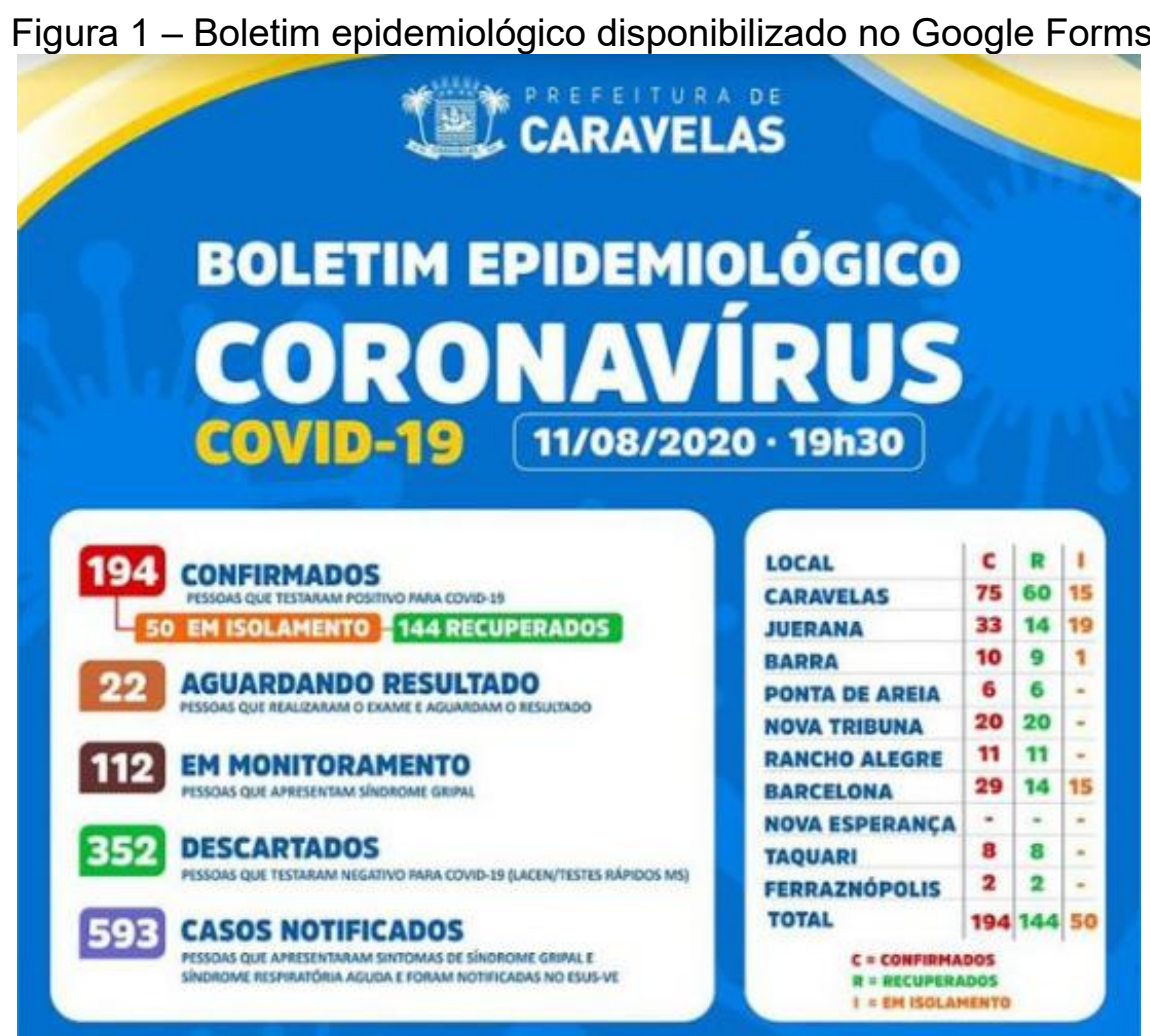

Fonte: Caravelas (2020)

E quanto as situações de natureza matemática elaboradas com base nesse boletim e inclusas nesse Google Forms? Foram quatro questões objetivas criadas sob a ótica de resolução de problemas. Tal escolha se justifica por ser esse caminho um dos pontos privilegiados da atividade matemática conforme pontua a BNCC (BRASIL, 2018). Apresenta-se como uma das metodologias ativas, muito debatida e discutida nos dias atuais e que pode ser explorada não somente em Matemática, mas também em outros componentes curriculares. É na prática problematizadora, fundamentada no princípio dialógico que segundo Freire (1987) o conteúdo programático se organiza, sem deixar de incluir à perspectiva de mundo dos educandos.

Com esse entendimento foram retomados conteúdos matemáticos, provavelmente, estudados por esses alunos em anos anteriores: operações básicas, ideias sobre frações e cálculo simples envolvendo porcentagem. Devido ao momento pandêmico, a orientação da direção e coordenação pedagógica da unidade escolar já mencionada anteriormente foi justamente que se trabalhassem, preferencialmente, os objetos de conhecimento matemáticos supostamente estudados por eles no último ano cursado. Além de registrar a sua resposta por meio do Google Forms ${ }^{1}$, o aluno também tinha que efetuar os cálculos no caderno conforme as orientações indicadas no formulário, representadas na Figura 2.

\footnotetext{
1 Disponível em: https://forms.gle/5DEiQpxwyLbmi8Yh7 (CAETANO, 2020b).
} 


\section{A Matemática a partir de um boletim epidemiológico (Coronavirus-Covid 19)}

Orientações:

Registrar as questões no caderno, bem como, os cálculos:

Não esqueça de datar (13/08/2020);

Ao responder este formulário, clique em enviar;

Quando você envia, sua atividade é automaticamente registrada. Bom desempenho!

Aluno

Texto de resposta curta

Fonte: Material da pesquisa (2020)

Para complementar a atividade com o intuito de estimular a criatividade, a inventividade e a imaginação, foi também proposto aos alunos que formulasse um problema a partir do boletim epidemiológico indicado, bem como, apresentasse a solução. Polya (1995) sugere inventar novos problemas e que possam ser resolvidos levando em conta aqueles já solucionados anteriormente. Nesse percurso, a "capacidade dos alunos de formular e resolver problemas desenvolve-se ao longo do tempo, como o resultado de um ensino prolongado, de várias oportunidades para a resolução de muitos tipos de problemas e do confronto com situações do mundo real" (DANTE, 2005, p. 37) ${ }^{2}$.

Sobre essa questão, a BNCC (BRASIL, 2018) recomenda que os alunos não apenas resolvam problemas, mas que também desenvolvam a prática de formular problemas a partir de contextos diversos. São várias habilidades envolvendo a expressão inicial "resolver e elaborar problemas", no que diz respeito ao trabalho com os objetos do conhecimento matemático sugeridas nesse documento, ao longo de todo o ensino fundamental e até mesmo no ensino médio. No $6^{\circ}$ ano, por exemplo, das 34 habilidades previstas para os alunos que cursam esse ano, oito habilidades estão sinalizadas com este foco. Por isso, considerou válido incluir nessa experiência além da resolução de problemas, a atividade de elaboração.

\footnotetext{
${ }^{2}$ Essa página refere-se ao manual pedagógico do professor indicado ao final do livro didático.
} 


\section{Análise dos resultados referentes às respostas registradas via Google Forms e os problemas formulados e resolvidos pelos alunos}

Nessa proposta de trabalho, assim como já citado, foram quatro questões de natureza objetiva $^{3}$ ancoradas à resolução de problemas e disponibilizadas no Google Forms. Para respondê-las, os alunos ao acessar tinham que consultar primeiramente a imagem do boletim epidemiológico local (Figura 1) anexada ao formulário, que por sinal, obteve o registro de 47 respostas. As vantagens de desenvolver uma atividade nesse recurso digital são diversas conforme já elencadas. Além de acompanhar de forma fácil e rápida os alunos que realizaram a atividade, os gráficos gerados permitem fazer a análise da perfomance das respostas registradas por eles em cada questão. Esses dados também podem ser obtidos por meio de uma planilha.

Nessa ótica, constatou-se que o primeiro problema foi aquele que os alunos tiveram o melhor desempenho. A situação envolvia basicamente a operação de adição. Portanto, bastava adicionar os dados referentes ao número de casos confirmados, aguardando resultado, em monitoramento, descartados e casos notificados para encontrar a solução $(194+22+112+352+$ 593 = 1273). Esse aproveitamento chegou a 85,1\%, o que significa 40 respostas enviadas corretamente, conforme mostra a Figura 3.

Figura 3 - Desempenho dos alunos no primeiro problema

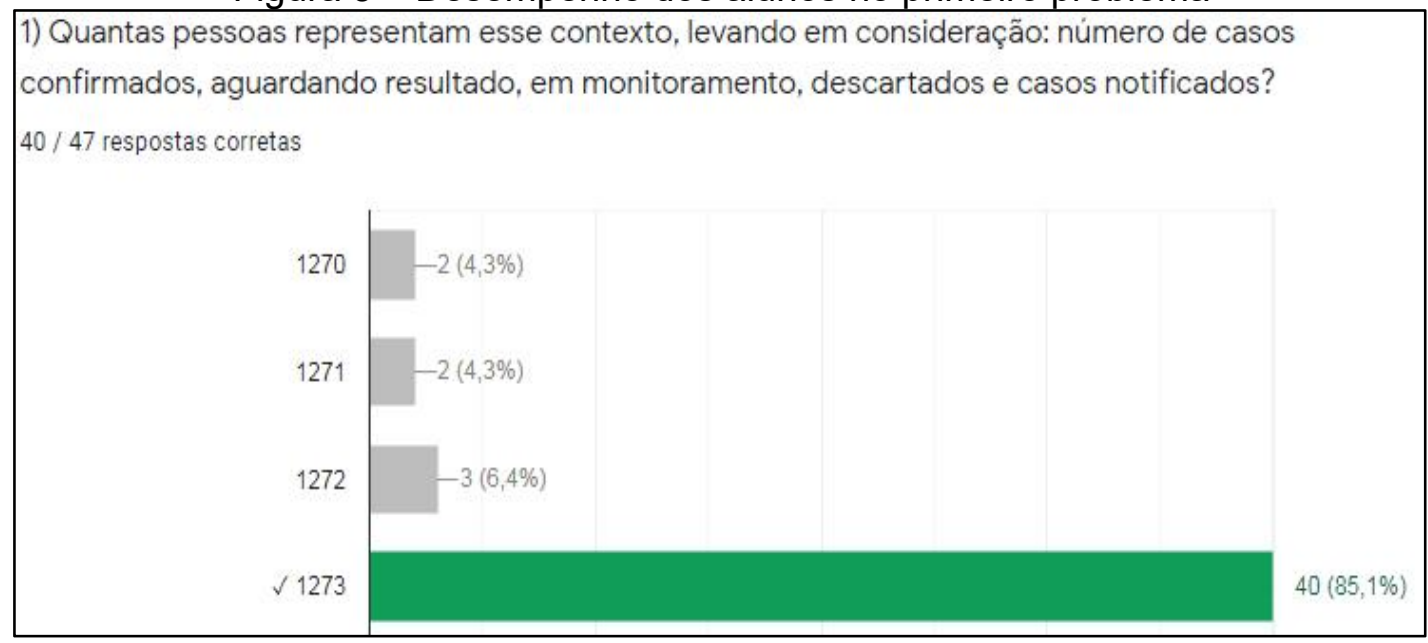

Fonte: Dados da pesquisa (2020)

\footnotetext{
3 1. Quantas pessoas representam esse contexto, levando em consideração: número de casos confirmados, aguardando resultado, em monitoramento, descartados e casos notificados?

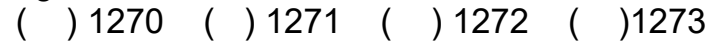

2. Em relação aos casos confirmados, qual é a operação matemática que indica o número de recuperados?

$\begin{array}{lllll}(\quad) & 194+50 & (\quad) 194-50 & (\text { ) } 194-144 & (\quad) 194+144+50\end{array}$

3. Calcule $1 / 3$ (a terça parte) de 57 . O resultado encontrado corresponde ao número de pessoas em isolamento de qual localidade pertencente ao município de Caravelas?

( ) Caravelas-Sede ( ) Juerana ( ) Ponta de Areia ( ) Barra

4. Caravelas tem aproximadamente 22000 habitantes (https://www.ibge.gov.br/cidades-e-

estados/ba/caravelas.html). Calcule 1\% dessa população. O valor encontrado representa um número maior, menor ou igual ao número de casos confirmados?

$($ ) maior ( ) menor ( ) igual
} 
O segundo problema, por sua vez, apresentou $72,3 \%$ de aproveitamento, com o registro de 34 respostas certas. O objetivo dessa questão era que os alunos descobrisse a operação matem ática que indicasse o número de pessoas recuperadas. Para isso, eles tinham que estabelecer a d iferença entre o número de casos confirmados (testados positivos para Covid-19) e dentro desse u niverso o número de pessoas em isolamento (em quarentena). Portanto, são 144 pessoas recuper adas, retratada na opção 194 - $50=144$. Este é o item correto a ser assinalado, o qual correspond e a essa situação problematizada.

Com um índice de acerto um pouco melhor que o problema anterior, o terceiro problema apresentou $74,5 \%$ de aproveitamento. Ideias sobre frações é o objeto de conhecimento matemático a ser usado no processo de resolução. A tarefa dos alunos consistia em calcular a terça parte de 57, fazendo 57: $3=19$. Em seguida, por meio das informações do boletim, tinham que identificar qual localidade pertencente ao município de Caravelas apresentava 19 pessoas em isolamento. O distrito de Juerana, distante cerca de $50 \mathrm{~km}$ da sede, é a comunidade que nesse instrumento didático indica essa quantidade de pessoas isoladas.

Finalmente, o quarto problema foi o que apresentou o menor aproveitamento, registrando 31 respostas certas das 47 registradas. A questão apresenta um cálculo simples envolvendo porcentagem, objeto de conhecimento matemático inserido na unidade temática números, e cujo desenvolvimento acontece a partir do $5^{\circ}$ ano do ensino fundamental de acordo com a BNCC (BRASIL, 2018). Como Caravelas tem uma população estimada em 22000 habitantes, esse problema consistia em calcular $1 \%$ dessa quantidade, que representa 220 . A partir da resposta obtida, o aluno tinha que consultar o boletim epidemiológico, tendo em vista verificar se o resultado encontrado era maior, menor ou igual ao número de casos confirmados da Covid-19 referentes a este município baiano. Nesta situação, a resposta correta a ser marcada era maior, uma vez que o número de pessoas infectadas representa 194.

E quanto aos problemas elaborados e resolvidos pelos alunos? O que eles revelam? Encaminhados por meio do WhatsApp, os problemas formulados, bem como solucionados pelos próprios alunos a partir do boletim epidemiológico, em linhas gerais, são semelhantes às questões objetivas propostas pelo professor no Google Forms. Essa tendência, de certo modo, está associada aos dizeres de Polya (1995) que enfatiza a importância de criar problemas e que possam ser solucionados com base em outros que já foram trabalhados e resolvidos. Propor atividades como esta é uma forma de valorizar a inventividade e a criatividade dos alunos. Pode ser ainda o ponto de partida que, possivelmente pode despertar neles, a possibilidade de se assumir como matemáticos (FREIRE, 1996b). 


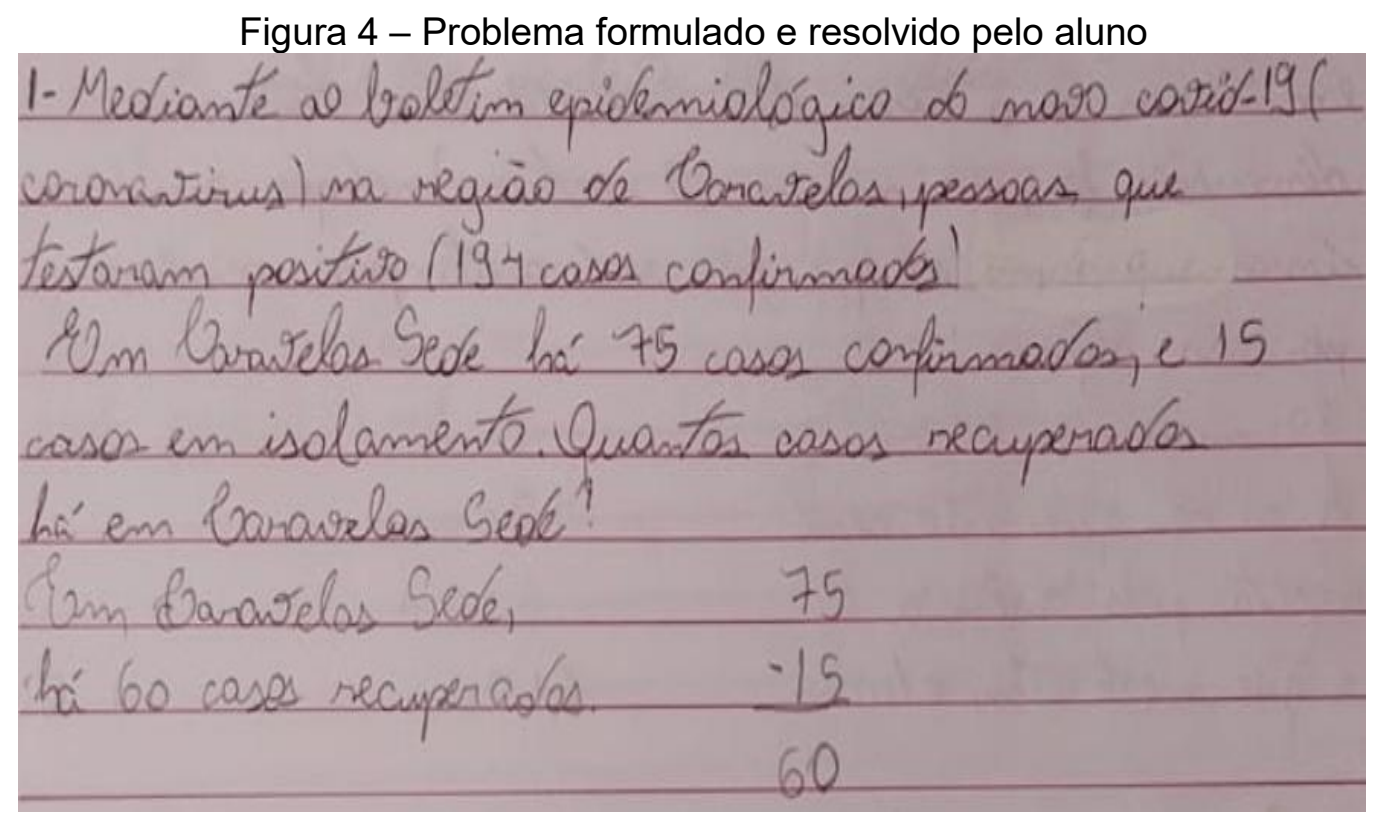

Fonte: Dados da pesquisa (2020)

Esta maneira de encaminhar a atividade em Matemática por meio de formulação e resolução de problemas é discutida por Dante (2010), que a define como ferramentas relevantes que contribuem para o desenvolvimento do raciocínio matemático do aluno. "A capacidade de formular problemas pode ser medida quando o professor sugere aos alunos que inventem seus próprios problemas a partir de alguns dados ou figuras" (DANTE, 2005, p. 37). No caso desse estudo, a imagem representativa utilizada para que os alunos inventassem e resolvessem seus problemas, teve como ponto de apoio o boletim epidemiológico da Covid-19 referente à localidade caravelense. Por isso, a importância de se propor atividades, em que diferentes áreas se interajam. Mas, por que estabelecer uma conexão entre a Matemática e diferentes temas concernentes a outras áreas do saber?

Diante desse enfoque, propor tarefas que aproximem o conhecimento matemático e assuntos de outras áreas do conhecimento, como situações do meio social vinculadas ao campo da saúde aqui retratadas e ainda, articuladas aos processos de resolução de problemas se mostraram fundamentais e necessárias. São contextos interessantes e significativos que dialogam com contextos existenciais em que os alunos estão inseridos, e que fazem parte do seu dia a dia. Esse exercício, dada a sua importância e de preferência com o auxílio dos recursos digitais, não deve ficar de fora da atividade matemática.

\section{Considerações finais}

Este trabalho é resultado de uma prática de ensino e aprendizagem desenvolvida remotamente junto aos alunos do $6^{\circ}$ ano de uma unidade escolar pertencente à rede de ensino do município de Caravelas, Extremo Sul baiano. Teve como intuito estabelecer uma relação entre a 
Matemática e o contexto pandêmico da Covid-19 por meio de um boletim epidemiológico local, referência norteadora. Por meio da metodologia de resolução de problemas proposta no Google Forms, sem perder de vista, sobretudo, as reflexões freireanas e as orientações da BNCC criou-se possibilidades para que os objetos de conhecimento matemático imbricado as informações sobre a pandemia do novo coronavírus fossem considerados, permitindo aos alunos a oportunidade de estabelecer essa relação.

Fica patente que ações que promovem o diálogo entre os diferentes conhecimentos, principalmente quando essa interação envolve uma situação concreta atual, tem uma forte tendência de tornar o processo de ensino e aprendizagem mais integrado e consolidado, uma vez que não há espaço para a compartimentação e a fragmentação dos saberes. Fomentar atividades dessa natureza, sem sombra de dúvidas, favorece o aprendizado, pois diversifica, dinamiza e enriquece o binômio ensinar e aprender de Matemática. Além disso, quando esse encaminhamento está atrelado à utilização dos recursos tecnológicos, de certo modo, atrai e desperta o interesse na realização da tarefa. Nesse sentido, não se pode perder de vista o papel relevante que têm os recursos digitais nessa condução.

As abordagens geradas no delineamento desse estudo mostrou que o fazer matemático não deve abster das situações matematizadas voltadas aos acontecimentos reais e temas atuais que estejam ligados de alguma forma à vida do aluno, como é o caso desse momento pandêmico da Covid-19 que, lamentavelmente, todos nós estamos passando. Partindo desse pressuposto, acredita-se que esses momentos reflexivos e investigativos são formas viáveis e significativas de construção do conhecimento matemático. Portanto, são imprescindíveis no que tange ao exercício matemático.

\section{Referências}

BRASIL. A área de Matemática. In: Base Nacional Comum Curricular. Brasília: MEC, 2018. p. 265-320. Disponível em: http://basenacionalcomum.mec.gov.br/images/BNCC EI EF 110518 versaofinal site.pdf. Acesso em: jan. 2021.

CAETANO, Marcos Antônio Guedes. Dando vez e voz aos alunos da EJA: promovendo um fazer matemático dinâmico. Cidadania em Ação: Revista de Extensão e Cultura, Florianópolis, SC, v. 4, n. 2, jul./dez. 2020a. DOI: https://doi.org/10.5965/259464124227.

CAETANO, Marcos Antônio Guedes. A Matemática a partir de um boletim epidemiológico (Coronavírus-Covid-19). 2020b. Disponível em: https://forms.gle/5DEiQpxwyLbmi8Yh7. Acesso em: jan. 2021.

CARAVELAS. Boletim Epidemiológico Coronavírus/Covid-19. Prefeitura Municipal de Caravelas. 11 ago. 2020. Disponível em: https://www.caravelas.ba.gov.br/coronavirus/. Acesso em: jan. 2021. 
D’AMBRÓSIO, Ubiratan. Educação Matemática: da teoria à prática. Coleção Perspectiva em Educação Matemática. Campinas, SP: Papirus, 1996.

DANTE, Luiz Roberto. Formulação e resolução de problemas de Matemática: teoria e prática. 1. ed. São Paulo: Ática, 2010.

DANTE, Luiz Roberto. Tudo é Matemática. 2. ed. São Paulo: Ática, 2005.

FREIRE, Paulo. Pedagogia da autonomia: saberes necessários à prática educativa. 12. ed. São Paulo: Paz e Terra, 1996a.

FREIRE, Paulo. Congresso de Educação Matemática. [Entrevista cedida a Ubiratan D’Ambrósio e Maria do Carmo Domite Mendonça]. 1996b. Disponível em: https://www.youtube.com/watch?v=tKkkGY1co7s\&t=226s. Acesso em: jan. 2021.

FREIRE, Paulo. Pedagogia do oprimido. 17. ed. Rio de Janeiro: Paz e Terra, 1987. Disponível em: https://cpers.com.br/wp-content/uploads/2019/10/Pedagogia-do-Oprimido-Paulo-Freire.pdf. Acesso em: jan. 2021.

GROENWALD, Claudia Lisete Oliveira; SILVA, Carmen Kaiber da; MORA, Castor David. Perspectivas em Educação Matemática. Acta Scientiae, Canoas, RS, v. 6, n. 1, p. 37-55, jan./jun. 2004. Disponível em: http://www.periodicos.ulbra.br/index.php/acta/article/view/129. Acesso em: set. 2020.

ONUCHIC, Lourdes de la Rosa. A resolução de problemas na Educação Matemática: onde estamos e para onde iremos? In: JORNADA NACIONAL DE EDUCAÇÃO MATEMÁTICA, 4., JORNADA REGIONAL DE EDUCAÇÃO MATEMÁTICA, 17., 2012, Passo Fundo. Anais [...]. Passo Fundo: Universidade de Passo Fundo, 2012. p. 1-15. Disponível em: http://anaisjem.upf.br/download/cmp-14-onuchic.pdf. Acesso em: ago. 2020.

POLYA, G. A arte de resolver problemas: um novo aspecto do método matemático. Tradução e adaptação: Heitor Lisboa de Araújo. Rio de Janeiro: Interciência, 1995. Disponível em: http://im.ufrj.br/ nedir/disciplinas-Pagina/Polya-Arte Resolver Problemas.pdf. Acesso em: jan. 2021.

SANTOS, Victor. Ensino remoto: como potencializar suas aulas com o Google Forms. Nova Escola, São Paulo, SP, 13 jul. 2020. Disponível em:

https://novaescola.org.br/conteudo/19492/ensino-remoto-como-potencializar-suas-aulas-com-ogoogle-forms. Acesso em: jan. 2021.

SERRAZINA, Maria de Lurdes; RIBEIRO, Deolinda. As Interações na Atividade de Resolução de Problemas e o Desenvolvimento da Capacidade de Comunicar no Ensino Básico. Bolema, Rio Claro, SP, v. 26, n. 44, p. 1367-1393, dez. 2012. Disponível em:

https://www.redalyc.org/pdf/2912/291226280012.pdf. Acesso em: set. 2020. 